\title{
Original article \\ Concealed pregnancy among school-going adolescents in South Africa: A qualitative study on risks for maternal and child health \\ Sogo France Matlala
}

\begin{abstract}
:
Objective: Concealed pregnancy is a public health concern with risks to girl-education as well as maternal and child health. This paper focuses on concealed pregnancy amongst adolescents attending schools in Limpopo province of South Africa. It defines concealed pregnancy, some reasons for concealment, methods used, partners in crime and implications for girl-education as well as maternal and child health. Materials and methods: A qualitative and exploratory study using in-depth interviews with 10 pregnant adolescents attending school, five parents and 10 educators on their experiences of caring for pregnant adolescents attending school was conducted. Results and Discussion: Results show that pregnant adolescents attending school conceal their pregnancies using various methods of keeping a secret, telling a lie, wearing baggy clothing, isolating and hiding among other students in overcrowded teaching spaces. They participate passively in learning activities to evade attention to themselves. Some authority figures such as educators and parents as well as other students are accomplices. Conclusion: To conceal pregnancies, pregnant adolescents attending schools flout antenatal care, thus increasing risks to women and children's health. They also show lack of attentiveness to learning activities at school, thus losing chances to achieve an education.
\end{abstract}

Keywords: teenage pregnancy; parental involvement; exercises in pregnancy; school health services; maternal and child health

Bangladesh Journal of Medical Science Vol. 19 No. 04 October'20. Page : 620-624 DOI: https://doi.org/10.3329/bjms.v19i4.46616

\section{Introduction}

South Africa is facing challenges of unplanned and unwanted pregnancies amongst adolescents attending schools ${ }^{1}$. There is no coordinated care for them to go on with schooling while having access to antenatal care (ANC) ${ }^{2}$. As such some conceal their pregnancies. Concealed pregnancy refers to when a woman, who is aware of being pregnant, intentionally keeps her pregnancy hidden from some people, particularly authority figures. A pregnant woman concealing pregnancy may not go for ANC or may only go after twenty weeks' gestation, which means that pregnancy can be concealed for some few months or in some cases until birth ${ }^{3-7}$. This definition of concealed pregnancy allows for some degree of confession where the pregnant woman divulges to a trustworthy person or persons who would conspire to conceal ${ }^{5}$. Concealed pregnancy happens in women of various social backgrounds and parity ${ }^{8}$. It is a public health concern with risks to maternal and child health as some women who conceal their pregnancies do not attend $\mathrm{ANC}$ as recommended ${ }^{9-10}$ This paper focuses on concealed pregnancy amongst adolescents attending schools in Limpopo province of South Africa. Limpopo is amongst the provinces with the highest number of pregnant learners in both primary and secondary schools ${ }^{11}$. The paper defines concealed pregnancy, discusses reasons for concealment, methods used, authority figures as accomplices to concealment and implications for girl education, maternal and child health.

\section{Materials and Methods}

The researcher conducted in-depth interviews with 25 purposively selected pregnant adolescents, their parents and their educators, using an interview guide, and recorded them with a voice recorder. In addition, field notes were collected immediately after the end of each interview. Respondents were asked for and agreed to the use of a voice recorder. Pregnant adolescents and their educators were interviewed at their schools while parents were interviewed at locations of their choice outside school premises.

Correspondence to: Sogo France Matlala, email: France.Matlala@ul.ac.za, Department of Public Health, University of Limpopo, South Africa 
The researcher interviewed educators and pregnant adolescents between lessons, as they were available, to ensure that teaching and learning activities are not disturbed. Respondents were interviewed individually, for between 45 and 60 minutes, until saturation of data was reached. To analyse data, the researcher transcribed voice recordings verbatim, wrote them in the form of a table to get them ready for line-by-line coding, and then used Tesch's open coding process ${ }^{12-13}$. Subsequently, the researcher gave an independent coder (experienced in qualitative research and reproductive health) all transcriptions and field notes to analyse and the codes found were matched with those found by the researcher. The two coders met to discuss and agree on the final codes.

The study respected research ethics principles of beneficence, respect for persons and justice by obtaining ethical clearance, asking for voluntary participation and obtaining permission from relevant authorities to access respondents ${ }^{2}$. This paper is part of a doctoral study on caring for pregnant adolescents going to schools in Limpopo Province of South Africa, as such, ethical clearance (HSHDC/185/2013) was provided by a relevant university. Approval to visit schools to collect data was given by managers at a provincial department of basic education, circuit offices and participating schools. All respondents consented to participate and signed consent forms, with pregnant adolescents assenting while their parents consented for them as they were below the age of consent to participate in research. The researcher satisfied credibility, transferability and confirmability, which are methods to ensure trustworthiness of qualitative studies ${ }^{14}$.

Ethical clearance: The study respected research ethics principles of beneficence, respect for persons and justice by obtaining ethical clearance.

\section{Results}

Because of saturation of data, 25 respondents, being 10 pregnant adolescents, 10 educators and five parents took part in the in-depth interviews. The 25 respondents were from four different secondary schools in Limpopo Province of South Africa. One parent was a male while the rest were females. One of the parents that shared their experiences of being a parent to a pregnant adolescent attending school was an educator at a school that did not participate in this study. Six educators were females while the remaining four were males. Three themes and six subthemes emerged with the themes showing reasons for concealment, methods to conceal and partners in crime. The sub-themes show fear of reaction and the need to remain in school as reasons for concealment; conveying false impression and wearing concealing clothing as methods to conceal while adult authority figures as accomplices to concealment are parents and educators. Table 1 presents a summary of the themes and sub-themes found, with narratives. Summarising themes in a table helps readers to get a comprehensive view of the findings ${ }^{15}$. The quotes from the transcripts show voices of pregnant adolescents, their parents and educators.

Table1. Summary of Themes and Sub-themes with Narratives

\begin{tabular}{|c|c|c|}
\hline Themes & Sub-themes & Narratives \\
\hline $\begin{array}{l}\text { Reasons for } \\
\text { concealment }\end{array}$ & $\begin{array}{l}\text { Fear of parental } \\
\text { reaction and of } \\
\text { the stigma of } \\
\text { pregnancy outside } \\
\text { marriage }\end{array}$ & $\begin{array}{l}\text { 'I was very shy.... of what people } \\
\text { would say, of what my parents would } \\
\text { say, of what my teachers would } \\
\text { say and I was very disappointed' } \\
\text { (pregnant adolescent) }\end{array}$ \\
\hline & $\begin{array}{l}\text { To remain in } \\
\text { school }\end{array}$ & \\
\hline \multirow{5}{*}{$\begin{array}{l}\text { Methods to } \\
\text { conceal }\end{array}$} & $\begin{array}{l}\text { Conveying false } \\
\text { impression }\end{array}$ & $\begin{array}{l}\text { 'I vomited during classes, then at } \\
\text { lunchtime my teacher called me and } \\
\text { asked me what's going on, and then I } \\
\text { lied, I said I just ate a lot...too much } \\
\text { snacks and I didn't eat breakfast, but } \\
\text { then he saw that I was lying, he just } \\
\text { said 'it's ok" (pregnant adolescent) }\end{array}$ \\
\hline & \multirow{4}{*}{$\begin{array}{l}\text { Wearing } \\
\text { concealing } \\
\text { clothing }\end{array}$} & $\begin{array}{l}\text { 'I asked my mother to ask the } \\
\text { headmaster if I can come to school } \\
\text { and the headmaster agreed, but he } \\
\text { said if I come to school I must always } \\
\text { wear a blazer so that the stomach } \\
\text { does not show and people cannot see. } \\
\text { I went to school and attended the class } \\
\text { but the educators didn't know that I } \\
\text { was pregnant' (pregnant adolescent) }\end{array}$ \\
\hline & & $\begin{array}{l}\text { '... what made me believe that student } \\
\text { was indeed pregnant was the fact } \\
\text { that she was always wearing the } \\
\text { Drimac }{ }^{\circledR} \text { (a type of jacket) and even if } \\
\text { it was not cold.... she was like hiding } \\
\text { that pregnancy' (educator) }\end{array}$ \\
\hline & & $\begin{array}{l}\text { 'these days pregnancy is not easily } \\
\text { visible because kids can cover } \\
\text { themselves' (parent) }\end{array}$ \\
\hline & & $\begin{array}{l}\text { 'through putting on this Drimac }{ }^{\circledR} \\
\text {...either it was hot or cold, that } \\
\text { particular student will continue to put } \\
\text { on that particular garment, trying to } \\
\text { hide that physical appearance. At one } \\
\text { stage when we started somewhere in } \\
2008 \text {, we had such a case whereby } \\
\text { we didn't even notice a student } \\
\text { was pregnant as she hides it within } \\
\text { herself...' (educator) }\end{array}$ \\
\hline
\end{tabular}




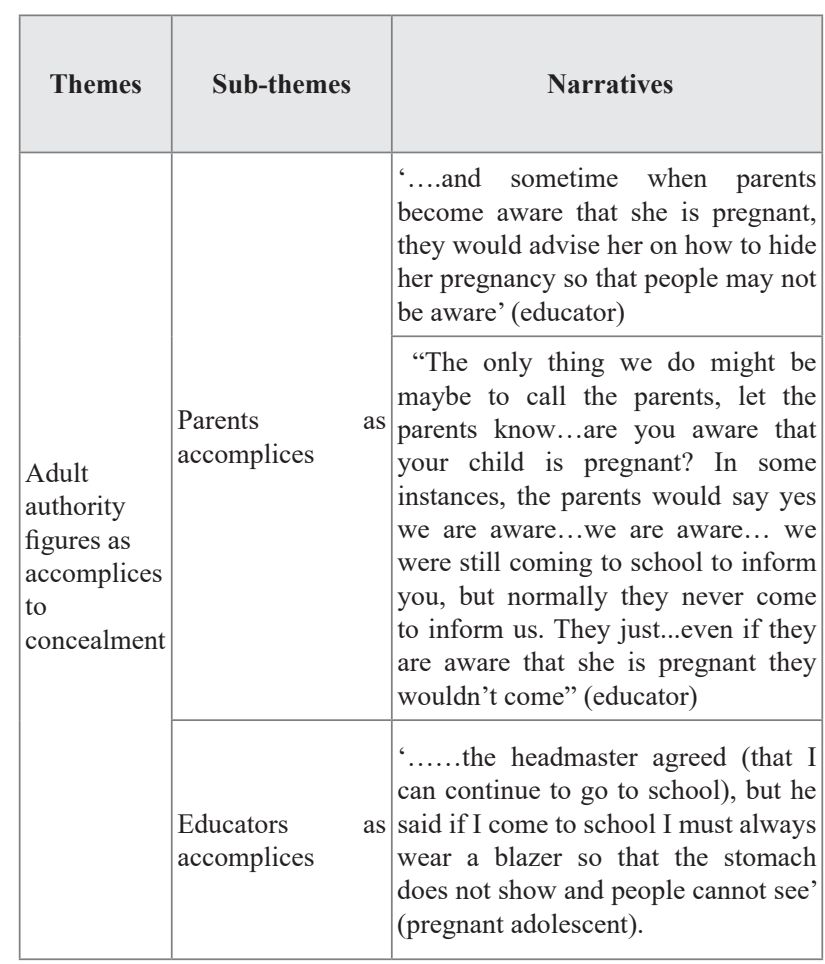

\section{Discussion}

The results show that adolescents conceal their pregnancies while educators and parents, who are adult authority figures ${ }^{16}$, are accomplices. A study in South Africa reveals that pregnant adolescents present late for ANC as compared to adults and have a small number of follow-up ANC visits. Pregnant women have a duty to initiate ANC before 12 weeks of pregnancy and make the first continuation appointment at 20 weeks ${ }^{1}$. This under-utilization of ANC suggests high concealment of pregnancy by adolescents.

Women conceal pregnancy for numerous reasons. The current study revealed that respondents concealed pregnancies so pregnant adolescents will continue to go to school. Some respondents thought concealing pregnancy would advantage pregnant adolescents as some of them dreaded reaction of their parents and the disgrace of pregnancy while not married. As the United Nations Educational, Scientific and Cultural Organization indicates, becoming pregnant while still in school could mean being expelled from school and home, and furthermore being humiliated and slated by family, community members and peers ${ }^{17}$. Due to societal practices in some communities, unmarried adolescents who become pregnant may bring severe punishments to themselves and their families.

Some pregnant adolescents concealed pregnancies from their parents in order to decide the outcome of their pregnancies on their own ${ }^{5}$. They are anxious that their parents may persuade them to either terminate pregnancies or take the child for adoption. Others dread their parents will sway them to keep the children and be mothers. Pregnant adolescents attending schools always conceal pregnancy as the pregnancy is unplanned and undesirable?

Respondents talked about various methods used to conceal pregnancy which encompassed telling a lie or conveying a false impression and wearing concealing clothing. One pregnant adolescent narrated putting on a blazer while others described to have put on a jacket even when it was warm. A blazer and a jacket are pieces of school uniform set aside for cold days. Other studies reveal some pregnant women concealing pregnancies with baggy or loose-fitting clothes which conceal their changing physique. Such women would wear heavy, oversized clothes even in summer or when it was warm ${ }^{1,5}$.

As indicated earlier, pregnant adolescents conceal their pregnancies to either their parents, educators or to both. Some divulge to their parents only while others divulge to some educators alone and pleads with them to conceal to others, thus becoming partners in crime or accomplices. Sometimes other students who are aware of the pregnancy also assist with concealment. This study reveals that some adult authority figures such as parents and educators assist with concealment. Some educators who were aware of pregnancy counselled pregnant adolescents to conceal their pregnancies. There are cases where pregnant adolescents revealed their pregnancies to their parents, but their parents were unwilling to inform the educators. At times some educators may know of the pregnancy but not share that information with other educators.

It takes time and strength of mind to conceal a pregnancy, thus pregnant adolescents attending school who conceal their pregnancies may be stressed and unable to pay attention to studies even when they remain in class ${ }^{5}$. Some refrain from hanging out with other students and become lonely while others shun active participation in learning activities. Wearing heavy clothes in warm weather conditions is likely to cause discomfort which may prevent a student to pay attention during lessons. This may lead to school drop-out due to poor academic performance, thus not contributing to girl-child education goal.

Remaining in school and getting some level of education is associated with increased ANC attendance which leads to positive maternal and child health outcomes. Some pregnant adolescents who conceal their pregnancies delay initiating ANC 
attendance while others do not attend at all ${ }^{6}$. Some of those concealing pregnancies fail to adapt their style of living in line with ANC recommendations to accommodate their pregnancies, in order to evade being visible, as such they risk their health and those of their unborn children. Others continue with usual activities like taking part in sports which can cause damages to the mother and her unborn child. Although exercising is encouraged for everyone, pregnant women are advised to avoid activities that involve physical contact and have increased chances of falling. Pregnant women should consult healthcare professionals if they want to take part in sport so that contraindications, if any, can be identified ${ }^{18}$. There are cases of pregnant adolescents who successfully conceal their pregnancies until labour and also conceal birth by delivering without medical care. Delivering without medical care may push away the mother and child from accessing postnatal care and child health services thus remaining outside the formal health services ${ }^{19}$. Some of those who succeed in concealing both pregnancy and birth throw away or kill their new-born babies ${ }^{4}$. Maternal and child health risks take place as there are no ANC visits to assess and monitor health and development of both the mother and the child ${ }^{1}$. A concealed pregnancy may, due to lack of health assessment and monitoring, result in severe complications and possibly death of either the woman or her child ${ }^{10}$.

\section{Conclusion}

This study revealed that pregnant adolescents attending schools conceal their pregnancies so they will avoid being expelled from school. They use various methods and need some parents, educators and other students as accomplices. To conceal pregnancies, some pregnant adolescents attending schools flout ANC, thus increasing risks to the health of women and children. Some of them also show lack of interest in learning activities at school, thus losing chances to achieve an education. Consequently, parents, educators and school health nurses have a duty to work collectively to support pregnant adolescents attending schools so they stay in school without concealing their pregnancies and can attend ANC. Research on innovative strategies to prevent pregnancy amongst adolescents attending school should be continued. Providing social support to those already pregnant is important to retain them in school and facilitate access to ANC. Those innovative strategies should not leave adolescent boys and men behind.

\section{Conflict of interest}

The author declares no competing interest

\section{Author's contribution}

SFM is the idea owner of this study and is responsible for Study design, Data gathering, Analysis and interpretation of data, Writing and submitting manuscript

\section{Source of funds}

This study was funded by the Postgraduate Bursary at University of South Africa and the National Research Foundation. 


\section{References:}

1. Govender T, Reddy P, Ghuman S. Obstetric outcomes and antenatal access among adolescent pregnancies in KwaZulu-Natal, South Africa. S Afr Fam Pract. 2017 1-7. https://doi.org/10.1080/20786190.2017.1333783

2. Matlala SF. A Model for the Facilitation of Health for Pregnant Students Attending Secondary Schools in Limpopo Province [dissertation]. Pretoria: University of South Africa; 2016. http://uir.unisa.ac.za/ handle/10500/23371

3. Tighe SM and Lalor JG. Concealed pregnancy: a concept analysis. $J A d v$ Nurs. 2016. 1(72):50-61. https://doi. org/10.1111/jan.12769

4. Tighe SM and Lalor J. Concealed pregnancy and newborn abandonment: a contemporary 21 st century issue. Part 1. Pract Midwife. 2016. 19(6):12-5.

5. Conlon C. Concealed pregnancy: a case study approach from an Irish setting, Dublin: Crisis Pregnancy Agency. 2006. http://hdl.handle.net/10147/305217

6. Friedman $\mathrm{SH}$ and Heneghan A, Rosenthal M. Characteristics of women who deny or conceal pregnancy. Psychosomatics. 2007; 48(2):117-22. https:// doi.org/10.1176/appi.psy.48.2.117

7. Jenkins A, Millar S and Robins J. Denial of pregnancy-a literature review and discussion of ethical and legal issues. J R Soc Med. 2011;104(7):286-91 https://doi. org/10.1258/jrsm.2011.100376

8. Nirmal D, Thijs I, Bethel J and Bhal PS. The incidence and outcome of concealed pregnancies among hospital deliveries: an 11-year population-based study in South Glamorgan. J Obstet Gynaecol 2006; 26(2):118-21. https://doi.org/10.1080/01443610500443303

9. Sorensen EA, Sincoff MZ and Siebeneck EA. The need for an effective student-athlete pregnancy and parenting policy. Journal of Issues in Intercollegiate Athletics. 2009; 1:25-45. http://csri-jiia.org/back issues/back

10. Dag ZO, Simsek Y, Turkel Y, Tulmac OB and Isik Y. Delayed diagnosis of PRES and eclampsia in a concealed pregnancy. Pan Afr Med J. 2014; 19: 299. https://doi. org/10.11604/pamj.2014.19.299.5628

11. Limpopo Department of Health and Social Development. 2011. Factors Associated with Teenage Pregnancy in
Limpopo Province. Paper presented at Provincial Health Research Day 2012. http://policyresearch.limpopo.gov. za/bitstream/handle/123456789/810/FACTORS\%20 ASSOCIATED $\% 20$ WITH $\% 20$ TEENAGE $\% 20$ PREGNANCY\%20IN\%20LIMPOPO\%20PROVINCE. pdf? sequence $=1$

12. Khandkar SH. Open coding. University of Calgary. 2009;23.

13. Creswell JW. Research Design: Qualitative, Quantitative and Mixed methods approach. 4th ed. London: Sage Publications, Inc. 2014.

14. De Vos AS, Strydom H, Fouché CB and Delport CSL. Research at grass roots for the social sciences and human service professions. 4th ed. Pretoria: Van Schaik Publishers, 2011.

15. Charlick SJ, McKellar L, Fielder A and Pincombe J. Interpretative Phenomenological Analysis: Implementing Research to Influence Breastfeeding Education. Int J Childbirth Educ 2015. 30(2):49-54. http://researchoutputs.unisa.edu.au/11541.2/115537

16. Wadham B, Owens L and Skryzpiec G. Taking Relationships to School: power, authority and identity work in young people's dispositions to schooling. Power and Education. 2014,6(2):130-44.https://doi. org/10.2304/power.2014.6.2.130

17. United Nations Educational, Scientific and Cultural Organization. Early and unintended pregnancy: Recommendations for the education sector Technical Brief. 2017 http://www.unesdoc.unesco.org/ images/0024/002484/248418e.pdf

18. Mottola MF, Davenport MH, Ruchat SM, Davies GA, Poitras VJ, Gray CE et al. 2019 Canadian guideline for physical activity throughout pregnancy. Br J Sports Med. 2018 1;52(21):1339-46.http://dx.doi.org/10.1136/ bjsports-2018-100056

19. Wahed T, Zaman S, Huda F, Jiayu L, Sultana S, Alam A, Panza A and Somrongthong R. A narrative review of the literature on the reproductive health of female sex workers having age below twenty years. Bangladesh J. Med. Sci.2019,19(1):17-31. https://doi.org/10.3329/ bjms.v19i1.43870 